\title{
INTERNAL StRUCTURES OF KNOWN Pinctada maxima Pearls: Natural Pearls from Wild Marine Mollusks
}

Artitaya Homkrajae, Areeya Manustrong, Nanthaporn Nilpetploy, Nicholas Sturman, Kwanreun Lawanwong, and Promlikit Kessrapong

Natural pearls form in mollusks without any human assistance, whereas cultured pearls form as a result of human intervention. In general practice, the identification of natural versus cultured pearls is determined by the internal structure revealed by X-ray techniques, particularly real-time microradiography (RTX) and X-ray computed microtomography $(\mu-C T)$. Interpretation of the results is based on reference samples studied previously. Therefore, a reference database founded on reliable samples obtained directly from known sources is an important factor. The internal structures of 774 natural marine pearls collected in situ by two of the authors from freshly opened wild Pinctada maxima mollusks were studied in detail to gain a better understanding of the internal structural characteristics of natural $\boldsymbol{P}$. maxima pearls. Based on the internal features obtained from RTX and $\mu-C T$ analyses, the samples were classified into six broad growth structure types: (1) tight or minimal growth, (2) organic-rich concentric, (3) dense core, (4) void, (5) linear, and (6) miscellaneous structures. Tight or minimal growth structures are typically observed in natural pearls and was noted in the majority of these samples. Some exhibited particular forms of organic-rich concentric, void, or linear structures resembling those previously observed and reported in some non-bead cultured (NBC) pearls produced from the same mollusk species. Such overlapping features demonstrate the challenges of distinguishing some natural and NBC pearls submitted to gemological laboratories. This article will present the diverse range of internal features found in natural $P$. maxima pearls, discuss the complexities sometimes encountered during the identification process, and share the protocols GIA applies in such situations. The work strengthens GIA's reference collection database on the internal structures of pearls, supporting its goal of providing dependable results on pearls submitted by clients. In this context, the authors intend to conduct further studies on natural and cultured pearls of known origins from various environments and mollusks to make GIA's database even more comprehensive.

$\mathrm{P}$ earls are biogenic gem materials that may form naturally without human intervention, or with assistance from humans in a culturing process. Natural and cultured pearls often display similar external appearances and occasionally cannot be differentiated without examining their internal structures. Over the last century, scientists and gemological laboratories have used film X-radiography and digital real-time microradiography (RTX) to reveal these interior growth patterns (Alexander, 1941; Webster, 1950; Benson, 1951; Sturman, 2009; Scarratt and Karampelas, 2020). Around 2010, X-ray computed

See end of article for About the Authors and Acknowledgments.

Gems \& Gemologr, Vol. 57, No. 1, pp. 2-21,

http://dx.doi.org/10.5741/GEMS.57.1.2

(C) 2021 Gemological Institute of America microtomography ( $\mathrm{\mu}-\mathrm{CT})$ began to be applied to pearl testing. This application provides high-resolution 3D imaging of the morphological structures, allowing fine growth features to be viewed in greater detail compared to traditional X-radiography (Karampelas et al., 2010; Krzemnicki et al., 2010; Otter et al., 2014; Karampelas et al., 2017). RTX and $\mu-C T$ are the main techniques used today by GIA and other gemological laboratories for pearl identification.

As with most research, interpretation of the results is based on data collected over the years, as well as the experience of those performing the work. Thus, a sample's source or the way in which it was obtained are very important factors to consider when creating a reliable database (Pardieu and Rakotosaona, 2012; Vertriest et al., 2019). In accordance with its existing guidelines for collecting gemstone reference samples 
TABLE 1. GIA pearl sample classification codes.

\begin{tabular}{|c|c|}
\hline & Origin \\
\hline A-type: Collected in the field by a GIA gemologist diving to collect the shell at the source/farm & \multirow{4}{*}{ Known sample } \\
\hline A1 Collected in situ directly from a freshly opened mollusk (video and/or photo record available). & \\
\hline $\begin{array}{l}\text { A2 Collected from a freshly opened mollusk. However, unable to document where the pearl formed because it fell out } \\
\text { of the pearl sac during the opening process. }\end{array}$ & \\
\hline $\begin{array}{l}\text { A3 Collected from the bottom of a container after the mollusk's soft tissues have passed through a mechanical } \\
\text { separator. }\end{array}$ & \\
\hline B-type: Collected in the field by a diver/operator witnessed by a GIA gemologist at the source/farm & \multirow{4}{*}{ Known sample } \\
\hline B1 Collected in situ directly from a freshly opened mollusk (video and/or photo record available). & \\
\hline $\begin{array}{l}\text { B2 Collected from a freshly opened mollusk. However, unable to document where the pearl formed because it fell out } \\
\text { of the pearl sac during the opening process. }\end{array}$ & \\
\hline $\begin{array}{l}\text { B3 Collected from the bottom of a container after the mollusk's soft tissues have passed through a mechanical } \\
\text { separator. }\end{array}$ & \\
\hline C-type: Collected from a trusted source (pearl diver/farmer/manufacturer/dealer) & \multirow{3}{*}{ Reported sample } \\
\hline $\begin{array}{l}\text { C1 Bought/loaned/donated from a trusted source (diver, farmer, etc.) in the local market (close to the source) with } \\
\text { supporting information on sample origin. }\end{array}$ & \\
\hline $\begin{array}{l}\text { C2 Bought/loaned/donated from a trusted source (diver, farmer, etc.) in the international market with supporting } \\
\text { information on sample origin. }\end{array}$ & \\
\hline D-type: Collected from an unknown source or unfamiliar dealers/suppliers/farmers & \multirow{3}{*}{ Reported sample } \\
\hline $\begin{array}{l}\text { Bought/loaned/donated from unknown source in the local market (close to the source) with supporting } \\
\text { information on sample origin. }\end{array}$ & \\
\hline $\begin{array}{l}\text { D2 Bought/loaned/donated from unknown source in the international market with supporting information on sample } \\
\text { origin. }\end{array}$ & \\
\hline E-type: No information about how the pearl was collected & \multirow[b]{2}{*}{ Unknown sample } \\
\hline $\begin{array}{l}\text { E1 Bought/loaned/donated from an unknown or unfamiliar source, but lacking any records/documents on sample } \\
\text { origin. }\end{array}$ & \\
\hline
\end{tabular}

in the field, GIA has applied pearl sample classification codes reflecting the different degrees of origin dependability (table 1). Those listed as A-type samples are the most dependable, while E-type samples are the least dependable. Collecting pearls directly from freshly opened mollusks is the ideal situation (A and B type), but this is not always possible, especially when it comes to natural pearls. In many cases, research can only be carried out on samples purchased or loaned from pearl farmers or reputable dealers $(C$ and $\mathrm{D}$ type). These samples are often described as being "reportedly" from a source or mollusk, and in most cases they serve as useful references in pearl identification matters. However, there are occasions where these reported samples are not sufficiently dependable to reach confident determinations, and more reliable reference samples are needed. E samples lack specific origin information, but can still be useful for some research such as color treatment or surface quality enhancement comparisons. A reference collection constructed of "known samples" that carefully documents how, when, and where they were acquired is an essential foundation for research on origin identification. Samples with known origin provide the highest degree of data reliability.
Pinctada maxima is a well-known mollusk species in the Pinctada genus, which is widely dis-

\section{In Brief}

- Pearl identification (natural vs. cultured) is dependent on the internal structure obtained by X-ray techniques, in particular RTX and $\mu$-CT analyses.

- Interpretation of the results is based on reference samples collected over the years. Therefore, reliable samples obtained directly from known sources are critical.

- The internal structures of 774 natural marine pearls collected in situ from freshly opened wild Pinctada maxima mollusks were studied.

- Various forms of internal structures were observed. While the majority displayed tight or minimal growth structures, some exhibited particular forms of organicrich concentric, void, or linear structures similar to some NBC pearls, demonstrating the challenges of pearl origin identification.

tributed throughout the central Indo-Pacific region (Southgate and Lucas, 2008). As with other mollusks, it can produce natural pearls, though it is now more 


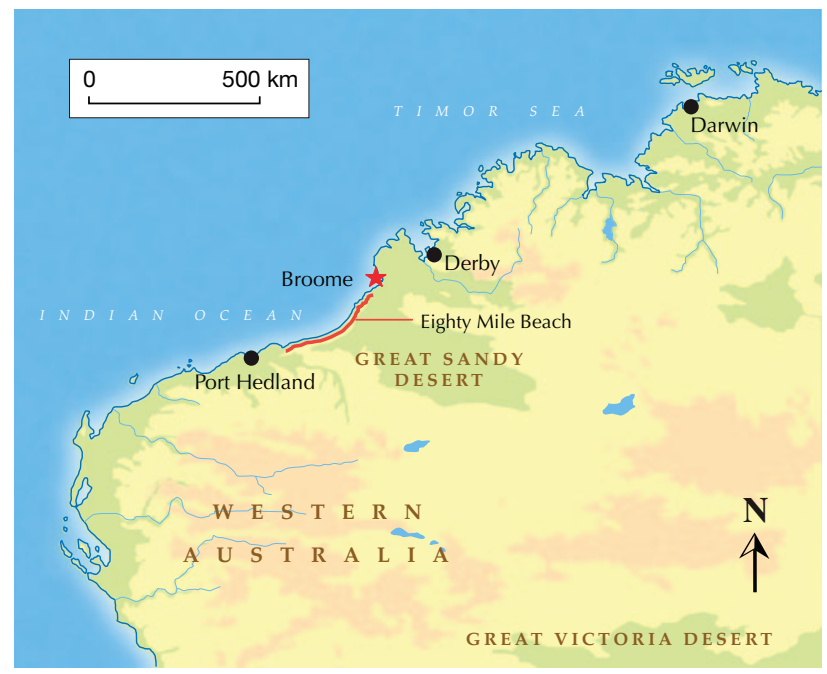

Figure 1. A map showing the location where GIA staff retrieved natural pearls produced by wild Pinctada maxima mollusks fished from the historical beds off Eighty Mile Beach in Broome, Western Australia. Image from Google Maps.

commonly associated with shell (mother-of-pearl) and cultured pearl production. Bead-cultured (BC) pearls are the primary product, although, some nonbead cultured $(\mathrm{NBC})$ pearls are also produced as a byproduct of the culturing process. NBC pearls (sometimes referred to as "keshi") are cultured pearls that form without a bead within a cultured pearl sac, instigated by human actions (CIBJO, 2017).

While the identification of most NBC pearls is straightforward, differentiating between some natural and NBC pearls can be challenging because both

Figure 2. A selection of natural P. maxima pearls retrieved directly from the wild mollusks examined in this study, shown on a P. maxima shell. The largest pearl weighs $19.94 \mathrm{ct}$. Photo by Nuttapol Kitdee.

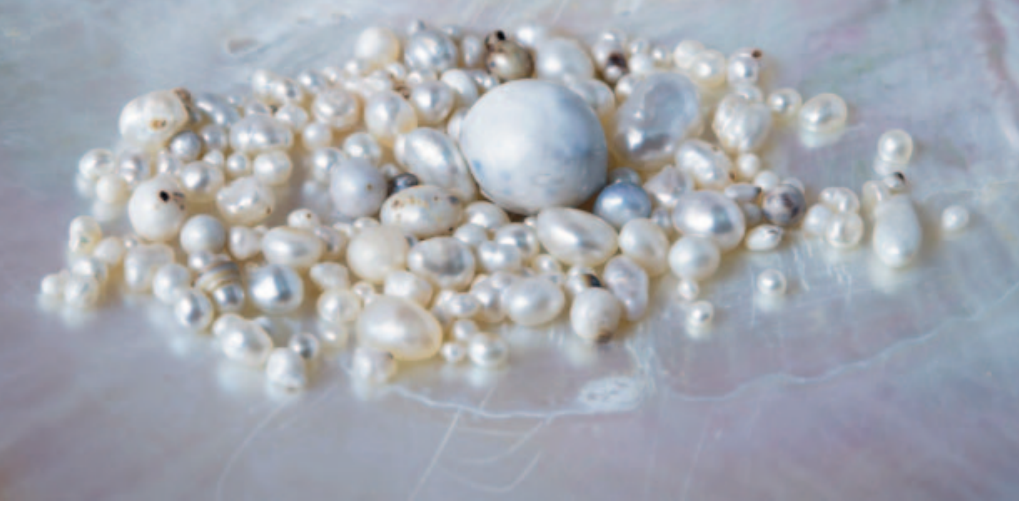

types are formed almost entirely of nacre and do not contain a shell bead nucleus. The reports on $P$. maxima pearls from Western Australia (Scarratt et al., 2012) and Lombok, Indonesia (Sturman et al., 2016), are GIA's pioneering studies on pearls of known origin. The samples in both reports were classified as Btype samples since they were collected in situ from mollusks by GIA gemologists after the shells were recovered, and the information for each pearl retrieved is well documented. In each case the samples helped to promote standardized identification calls on pearls produced from $P$. maxima mollusks since there are no questions concerning their origin. For this reason, GIA intends to continue studying samples of known origin from P. maxima in order to expand the dependable database of internal structures for gemologists to access when needed.

The authors have studied the internal structures of three different groups of known P. maxima pearls, and the various growth features observed within each group will be discussed in a series of three articles. This, the first installment, looks at the natural pearls retrieved directly from unoperated wild mollusks. The second article will cover NBC and BC pearls that were grown in cultured pearl sacs that developed from pieces of mantle tissue inserted into the gonad areas. The final article will address pearls that formed in the mantle area or adductor muscle, or were attached to the shell, of operated mollusks.

\section{MATERIALS AND METHODS}

In late September 2013, a GIA pearl team (authors $\mathrm{AH}$ and AM) with the assistance of the Paspaley Pearling Company, once again had the opportunity to visit the historical P. maxima mollusk beds off Eighty Mile Beach in Broome, Western Australia (Scarratt et al., 2012, figure 1). Although the main purpose of the pearling expedition off Eighty Mile Beach was to collect wild $P$. maxima shells from the ocean floor as a part of the Australian shelling quota system (WAMSC, 2015), GIA's primary objective was to collect natural pearls found in the mollusks. In total, 774 natural pearls were found in 20,488 opened mollusks (figure 2), and those authors present were able to retrieve pearls and record the exact locations where 370 of them formed within the mollusk (B1 sample type).

On opening the shells, the search started with a visual inspection of the soft organs for any obvious pearls. This was followed by a fingertip search to feel for any seed pearls or pearls that might have formed 


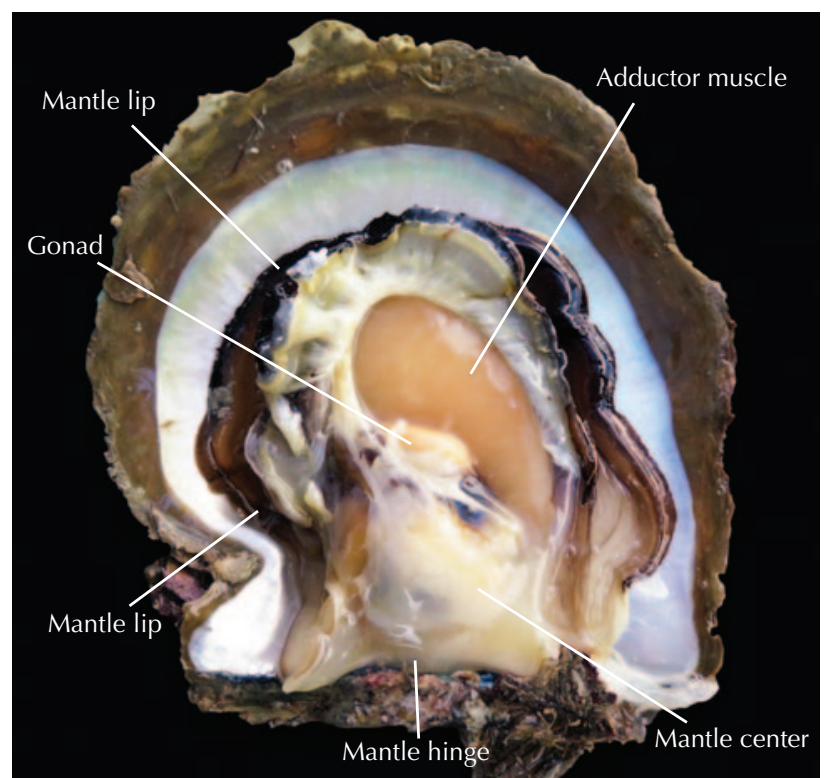

Figure 3. Searching for natural pearls in the mollusk body began with a visual inspection and then the soft organs (mantle lip, mantle hinge, mantle center, and adductor muscle) were explored with fingertips. Natural pearls were found in all areas, apart from the gonads, and some were found loosely attached to the shell surface. The mantle lip shown in the image is retracted; it originally extended to the shell's edge (ventral margin). Note: The naming convention was developed by GIA and initially presented in 2014. Photo by Nanthaporn Nilpetploy.

in areas hidden from view by the mantle that extended around the lip, down to the hinge and the central part (figure 3). The adductor muscle was also checked for the presence of pearls. The majority of pearls retrieved from the known positions were found in various parts of the mantle, either close to the lip, toward the hinge or in the central part of the mollusk (table 2). However, it was very interesting to see that some seed pearls were also found embedded in the adductor muscles (figure 4). As would be expected for natural wild shells, no pearls were found in the gonads. Moreover, a few were loosely attached to the shell surface, and were subsequently removed by applying gentle finger pressure. The latter are considered to be whole pearls and typically show circular

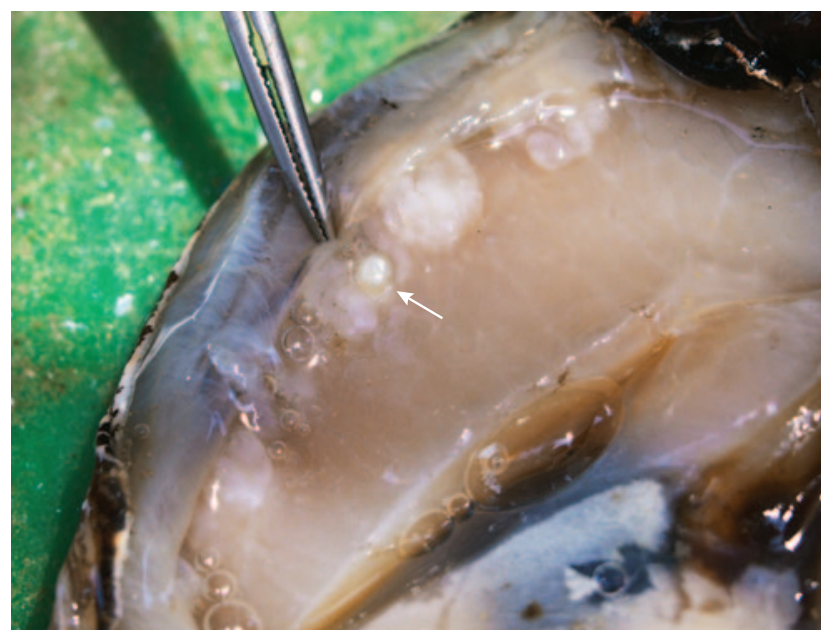

Figure 4. Aside from the mantle area, some seed pearls were found embedded in the adductor muscle. The pearl in the image (indicated by the white arrow) weighs 0.14 ct. Photo by Areeya Manustrong.

marks of organic-rich material on their surface where they were connected to the shell (Lawanwong et al., 2019). These findings are in keeping with the observations from Australian fisheries recorded by Kunz and Stevenson (1908):

Within the adductor muscle are found seed-pearls and small baroque; the large pearls are found embedded in the mantle, where their presence may be detected as soon as the shell is opened, the pearly gleam contrasting with the light blue of the mantle. Sometimes, though rarely, large pearls are found loose within the shell, whence they roll out when the shell is opened.

It came as no surprise that some specimens did not produce any pearls, while others contained more than one pearl. More commonly, pearls formed in individual sacs in adjacent areas (figure 5, left) or in separate areas within the mollusk, though in some cases several individual pearls formed within the same sac (figure 5, right).

Shell opening was carried out over eight days by several people on the vessel. The exact position in which some of the remaining 404 pearls formed inside the mollusks could not be documented because they fell out of the sac during the shell opening process (B2 sample type). This could have resulted

TABLE 2. Natural P. maxima pearl samples examined in this study.

\begin{tabular}{lccccc}
\hline $\begin{array}{l}\text { Position where } \\
\text { found in the mollusk }\end{array}$ & Mantle & Adductor muscle & Attached to shell & Unknown & Total \\
\hline Number of pearls & 217 & 138 & 15 & 404 & 774 \\
\hline
\end{tabular}



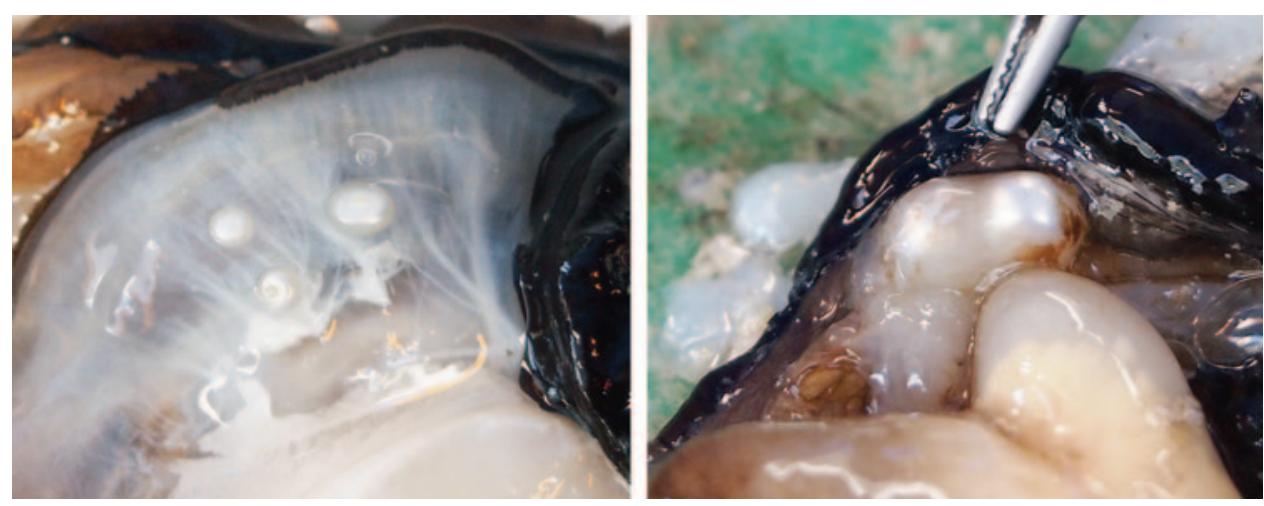

Figure 5. Pearls were commonly found in individual sacs in adjacent areas or in separate areas within the mollusk (left). However, some individual natural pearls were found together in the same pearl sac (right). Photos by Artitaya Homkrajae.

from the abrupt retraction of the mantle lip from the shell edge (ventral margin) when cutting through the mollusk or from the perforation of the pearl sac by a knife. The balance of the 404 pearls were recovered later in the process from the bottom of a container after the mollusks' soft tissues had passed through a mechanical separator (B3 sample type). Nonetheless, all the samples studied are undoubtedly classified as natural pearls of known origin, as they formed in wild mollusks (i.e., unbred, non-hatchery raised, unoperated) that had never been involved in any pearl culturing process. The measurements ranged from $0.49 \mathrm{~mm}$ to $16.16 \times 15.57 \times 13.24 \mathrm{~mm}$, and the weights ranged from negligible to $19.94 \mathrm{ct}$.

The internal structures of the 774 natural marine pearl samples, on loan to GIA, were recorded using RTX and $\mu-C T$ analyses. The RTX analysis was performed using a Pacific X-ray Imaging (PXI) GenX-90P $\mathrm{X}$-ray system with 4-micron microfocus, $90 \mathrm{kV}$ voltage, and $0.16 \mathrm{~mA}$ current $\mathrm{X}$-ray source with an exposure time of 200-400 milliseconds per frame, combined with a PerkinElmer 1512 flat panel detector with a maximum of 128 frames average and 74.8 micropixel pitch with $1944 \times 1536$ pixel resolution. The samples that showed intriguing or indistinct structures were selected for more detailed $\mu$-CT work to better view the internal structures. The $\mu$-CT work was carried out with a ProCon CT-mini X-ray system with a 5 -micron microfocus, $90 \mathrm{kV}$ voltage, and $0.18 \mathrm{~mA} \mathrm{X}$-ray current source. Two detectors with a frame grabber card were used to capture the results: a Hamamatsu flat panel detector C7921CA29 with 50 micropixel pitch and $1032 \times 1032$ pixel resolution, and a Varex 1207 flat panel detector with 74.8 micropixel pitch and $1536 \times 864$ pixel resolution. RTX and $\mu-C T$ data were collected in GIA's Bangkok laboratory. Because the work focused on the samples' internal structures, other aspects including physical, spectroscopic, and chemical characteristics are not presented.

\section{OBSERVATIONS AND RESULTS}

A natural pearl is the result of an accidental occurrence during the normal life cycle of a mollusk (Strack, 2006). Various conditions influence the formation of pearls, such as water environment and a mollusk's health (Gervis and Sims, 1992; Bondad-Reantaso et al., 2007), so it is common to find various types of internal structures in natural pearls, as well as cultured pearls. Based on the internal features obtained by RTX and $\mu-C T$ analyses, natural pearl samples can be separated into six broad growth structure types (figure 6):

1. Tight or minimal growth

2. Organic-rich concentric

3. Dense core

4. Void

5. Linear

6. Miscellaneous

From all 774 natural pearls examined in this study, 45 were selected in order to provide a representative overview of the various internal structures observed. The RTX and $\mu-C T$ results of each sample are shown in tables 3 through 8, along with the sample number, weight, and measurement in the first column and a macro image in the third column. The second column shows the image captured during each pearl's retrieval, if applicable, from within the mollusk. The position of each pearl is indicated by a black arrow and noted in the first column. Those listed as "unknown" were the ones where the pearl's position could not be documented because it fell out of the pearl sac during the opening process or was later recovered from the mechanical separator. The $\mathrm{RTX}$ and $\mu-C T$ results are grayscale images in which differing shades of bright and dark grayscale intensity correspond to X-ray density (i.e., the different degrees of attenuation the component materials have to X-rays). Mineralized materials such as arag- 
Summary of Internal Structures: Natural Pearl Samples

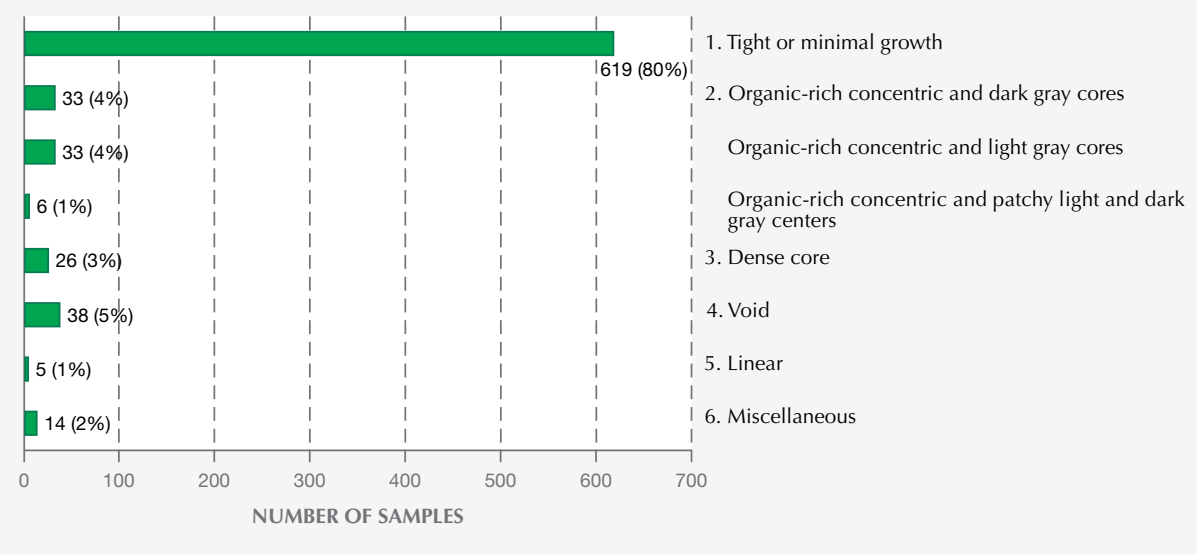

Figure 6. Summary of the six internal structures found in the 774 natural pearl samples studied, with the percentage of each structure type within the group. onite or calcite are denser or more radiopaque than organic-rich features or voids filled with gases and/or liquid; hence, an area composed entirely of aragonite will appear lighter than an area containing organicrich or void features which generally appear darker
(Wehrmeister et al., 2008; Sturman, 2009; Otter et al., 2014). [Note: In this article, the description of an internal structure as "dark gray" and "light gray" corresponds to its X-ray density, not its actual color.]

TABLE 3. Examples of natural pearls from wild mollusks with tight or minimal growth structures (type 1).

\begin{tabular}{|c|c|c|c|c|}
\hline Sample details & $\begin{array}{c}\text { Position where } \\
\text { found in the mollusk }\end{array}$ & Macro image & RTX image & $\mu$-CT image \\
\hline $\begin{array}{c}1-1 \\
\text { (mantle hinge) } \\
1.45 \mathrm{ct} \\
6.71 \times 5.62 \mathrm{~mm}\end{array}$ & & & & \\
\hline $\begin{array}{c}1-2 \\
\text { (mantle hinge) } \\
0.65 \mathrm{ct} \\
4.85 \times 4.57 \times 5.89 \mathrm{~mm}\end{array}$ & & & & \\
\hline $\begin{array}{c}1-3 \\
\text { (adductor muscle) } \\
0.30 \mathrm{ct} \\
3.98 \times 3.71 \times 3.00 \mathrm{~mm}\end{array}$ & & & & \\
\hline $\begin{array}{c}1-4 \\
\text { (mantle hinge) } \\
0.63 \mathrm{ct} \\
6.33 \times 4.25 \times 3.10 \mathrm{~mm}\end{array}$ & & & & \\
\hline
\end{tabular}

The position of the pearl in the mollusk is indicated by a black arrow. The white arrows indicate the more radiopaque (lighter gray) areas observed. 
TABLE 4. Examples of natural pearls from wild mollusks with organic-rich concentric structures (type 2).

\begin{tabular}{|c|c|c|c|c|}
\hline Sample details & $\begin{array}{l}\text { Position where } \\
\text { found in the mollusk }\end{array}$ & Macro image & RTX image & $\mu$-CT image \\
\hline \multicolumn{5}{|c|}{ Dark gray core } \\
\hline $\begin{array}{c}2-1 \\
\text { (mantle lip) } \\
2.20 \mathrm{ct} \\
8.29 \times 6.80 \times 6.22 \mathrm{~mm}\end{array}$ & & & & \\
\hline \multicolumn{5}{|l|}{$\begin{array}{c}2-2 \\
\text { (attached to shell) } \\
19.94 \mathrm{ct} \\
16.23 \times 15.65 \mathrm{x} \\
13.21 \mathrm{~mm}\end{array}$} \\
\hline \multicolumn{5}{|l|}{$\begin{array}{c}2-3 \\
\text { (mantle lip) } \\
1.38 \mathrm{ct} \\
6.40 \times 5.89 \times 5.78 \mathrm{~mm}\end{array}$} \\
\hline \multicolumn{5}{|l|}{$\begin{array}{c}2-4 \\
\text { (mantle center) } \\
0.37 \mathrm{ct} \\
4.05 \times 3.84 \times 3.55 \mathrm{~mm}\end{array}$} \\
\hline \multicolumn{5}{|l|}{$\begin{array}{c}2-5 \\
\text { (mantle lip) } \\
0.74 \mathrm{ct} \\
5.17 \times 4.60 \mathrm{~mm}\end{array}$} \\
\hline \multicolumn{5}{|l|}{$\begin{array}{c}2-6 \\
0.45 \mathrm{ct} \\
4.14 \times 3.76 \mathrm{~mm}\end{array}$} \\
\hline \multicolumn{5}{|l|}{$\begin{array}{c}2-7 \\
\text { (mantle lip) } \\
0.39 \mathrm{ct} \\
4.31 \times 3.93 \times 3.07 \mathrm{~mm}\end{array}$} \\
\hline \multicolumn{5}{|c|}{ Light gray core } \\
\hline $\begin{array}{c}2-8 \\
0.59 \mathrm{ct} \\
4.45 \mathrm{~mm}\end{array}$ & Unknown & & & \\
\hline $\begin{array}{c}2-9 \\
0.30 \mathrm{ct} \\
3.93 \times 3.73 \times 2.78 \mathrm{~mm}\end{array}$ & Unknown & & & \\
\hline
\end{tabular}

The position of the pearl in the mollusk is indicated by a black arrow. 


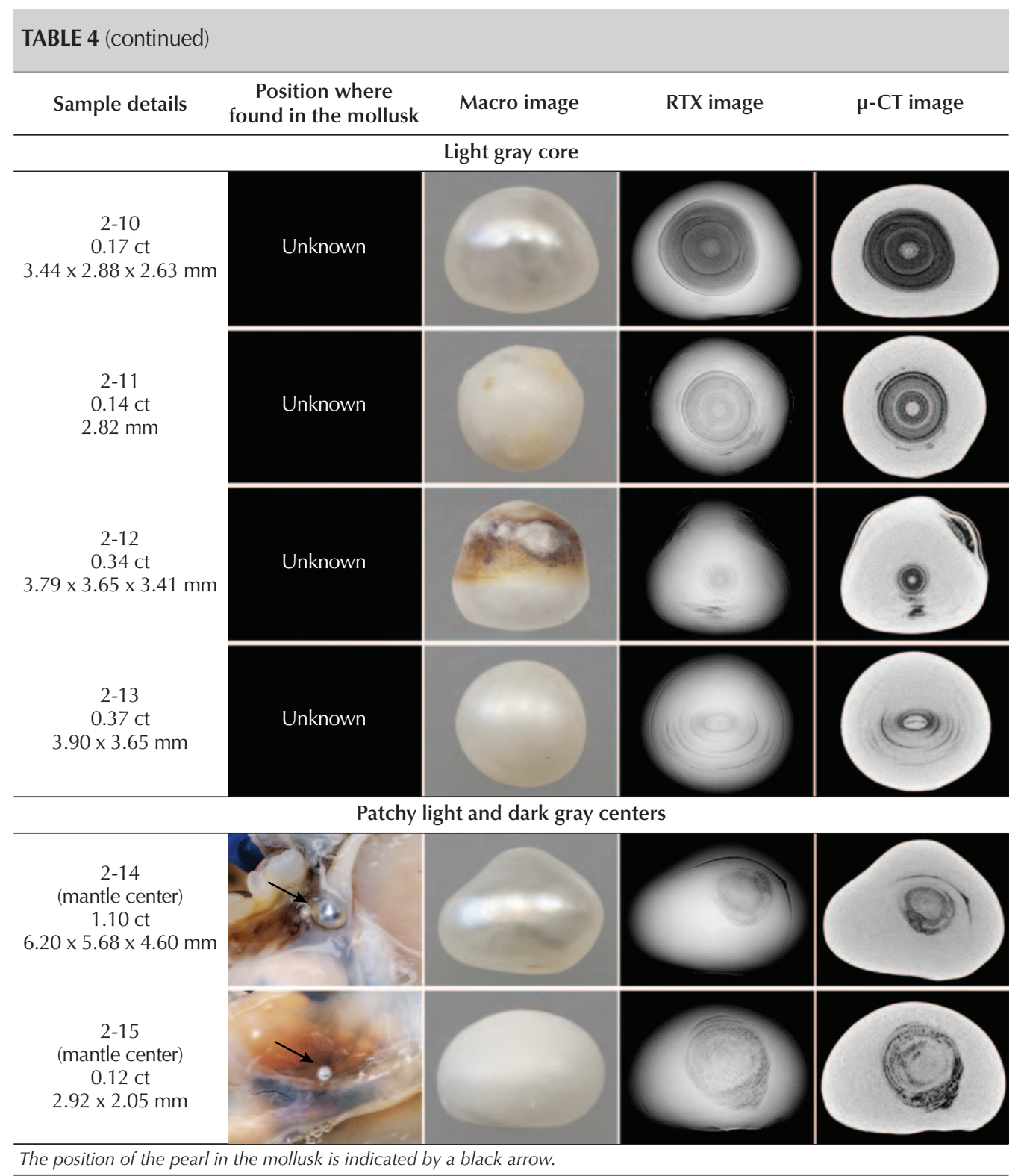

Type 1: Tight or Minimal Growth Structures. 619 samples $(\sim 80 \%)$ recovered displayed this structure. They lacked any clear internal growth structures, or only showed a few weak growth patterns (fine structural curved lines correlating with the pearl's shape) by RTX analysis (table 3). The majority of the pearls also revealed very little structure when examined by $\mu-C T$ analysis. In addition, slightly lighter gray (more radiopaque) areas were observed in some instances, as shown in samples 1-2 and 1-3 (indicated by white arrows). These areas may be composed of some material or substance that has a higher X-ray density than nacre. Since the pearls did not contain questionable internal features related to any type of cultured pearl formation, they would, in almost all cases, be identified as natural pearls.

Type 2: Organic-Rich Concentric Structures. Around $9 \%$ of the samples in this study displayed organicrich concentric structures of various sizes and patterns (table 4). They ranged from examples with a very small core (sample 2-1) to those with large concentric layered areas occupying almost half of the pearl's interior (sample 2-10). $\mu$-CT analysis clearly revealed cores with different forms, such as a dark gray core (more radiolucent), a light gray core (more radiopaque), or varying degrees of contrast with patchy light and dark gray centers within the con- 
centric structures. The dark gray cores are not empty spaces, but rather they are filled with a solid/semisolid organic-rich phase (samples 2-1 to 2-7). The sizes of the dark gray cores varied from small spots to large irregular areas shown in samples 2-6 and 27. The light gray cores appeared to be dense material and had a radiopacity similar to that of the outer nacre; hence, they are probably $\mathrm{CaCO}_{3}$. These cores varied in size, with the majority of them appearing small and rounded, as shown in samples 2-8 to 2-12. Sometimes the shape and structures varied, as in sample 2-13, which showed an ovoid core and a linear-appearing feature running across its center (magnified in figure 7). The structure of sample 2-13 was inconsistent with the majority of pearls in the group; it has never been observed in known or "reportedly" natural samples in our experience and has not been noted in the literature. This unusual structure may be challenging to identify, especially in laboratory conditions when information on the pearl's origin is unknown, and therefore greater care is needed in its interpretation. It could easily be misidentified as a NBC pearl since the majority of light gray cores observed in natural pearls are typically rounded, and off-round cores have been observed in known NBC pearls produced by the $P$. maxima mollusk (Manustrong et al., 2019). Moreover, the central feature within the core has a linear form, and such features have been observed in NBC pearls produced by various mollusk species. Similar linear features, although not exactly the same, are often considered sufficient evidence to classify pearls as NBC (Hänni, 2006; Sturman, 2009; Krzemnicki et al., 2010; Sturman et al., 2016; Nilpetploy et al., 2018a; Manustrong, 2018). RTX and $\mu$-CT imaging of samples
2-14 and 2-15 showed patchy concentric structures that appeared neither light nor dark gray, and these were due in part to differences in the organic content within the areas. These samples also lacked dark or light gray cores.

Type 3: Dense Core Structures. A small portion, approximately $3 \%$ of the group, contained solid light gray (more radiopaque) core features, usually single but sometimes multiple, at their centers (table 5). The X-ray attenuation of these cores closely matched some similar features observed in type 2 samples. However, they were not enclosed by clear organicrich concentric structures; hence, they were classified as a separate structural type, referred to here as a "dense core." These dense cores usually appeared as a single structure that was round, off-round, or irregularly shaped, and they were often associated with some faint organic-rich layers (samples 3-1 to 3-3). A few examples, such as samples 3-4 and 3-5, showed two or more cores that formed together as multi-nuclei. Irregular dense core structures have only been observed in natural pearls, in the authors' experience, and have not been reported in any NBC pearls. However, an off-round feature associated with the main core in sample 3-5 looks suspicious and could be construed as being a light gray $\mathrm{CaCO}_{3}$ "seed" feature sometimes found in NBC pearls (Krzemnicki et al., 2010, 2011; Nilpetploy et al., 2018a; Manustrong et al., 2019). Thus, if this pearl was tested without any supporting provenance, it could be interpreted as being NBC. Nevertheless, the greater detail revealed by $\mu-C T$ analysis showed faint growth layers inside the feature, in contrast to the $\mathrm{CaCO}_{3}$ "seed" features,

Figure 7. $\mu$-CT slices in three directions of sample 2-13 revealed an ovoid core and a linear-looking feature running through the center. Based on these two features, the pearl could possibly be misidentified as NBC if it were submitted for testing without any supporting information about its origin.
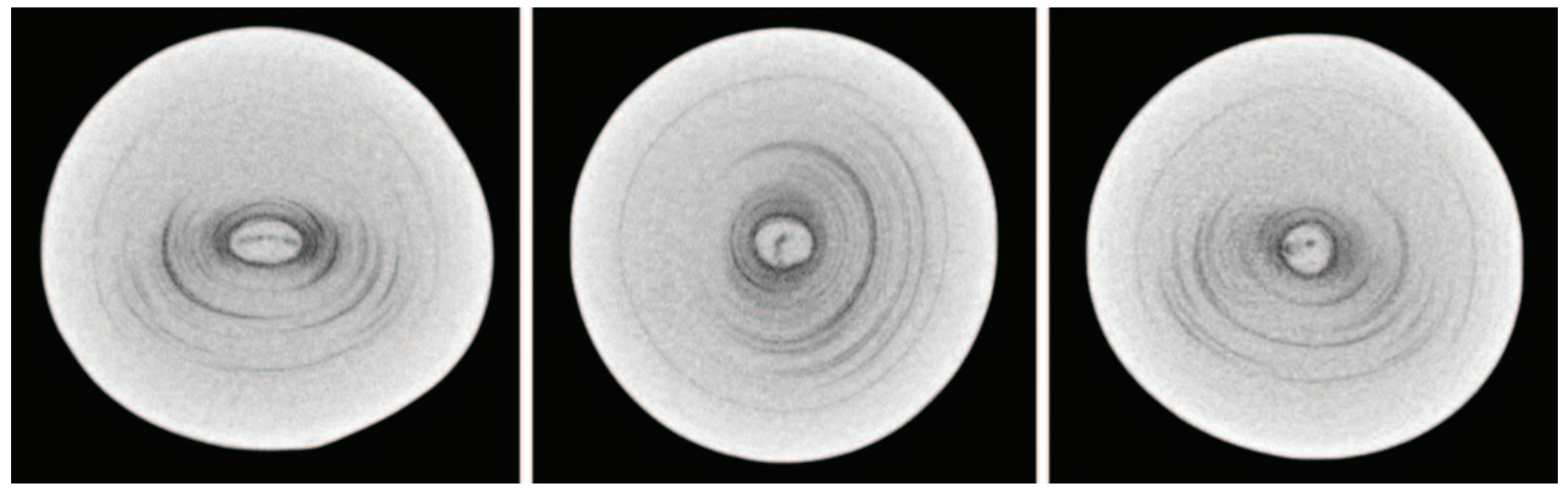
TABLE 5. Examples of natural pearls from wild mollusks with dense core structures (type 3).

\begin{tabular}{|c|c|c|c|c|}
\hline Sample details & $\begin{array}{l}\text { Position where } \\
\text { found in the mollusk }\end{array}$ & Macro image & RTX image & $\mu$-CT image \\
\hline $\begin{array}{c}3-1 \\
0.19 \mathrm{ct} \\
3.37 \times 2.97 \times 2.42 \mathrm{~mm}\end{array}$ & Unknown & & & \\
\hline $\begin{array}{c}3-2 \\
0.14 \mathrm{ct} \\
2.85 \times 2.68 \times 2.57 \mathrm{~mm}\end{array}$ & Unknown & & & \\
\hline $\begin{array}{c}3-3 \\
\text { (mantle hinge) } \\
0.50 \mathrm{ct} \\
5.92 \times 3.46 \times 3.22 \mathrm{~mm}\end{array}$ & & & & \\
\hline $\begin{array}{c}3-4 \\
1.55 \mathrm{ct} \\
7.02 \times 5.79 \times 5.60 \mathrm{~mm}\end{array}$ & Unknown & & & \\
\hline $\begin{array}{c}3-5 \\
\text { (mantle hinge) } \\
0.13 \mathrm{ct} \\
2.86 \times 2.76 \times 2.38 \mathrm{~mm}\end{array}$ & 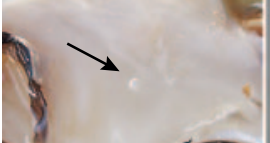 & & & \\
\hline
\end{tabular}

which are usually tight and contain no structure (magnified in figure 8). In this example, where the in- ternal structural characteristics overlap and do not correspond with the majority of structures observed

Figure 8. $\mu$-CT slices in three directions of sample 3-5 revealed a satellite off-round feature next to the main core. The feature has similarities to light gray $\mathrm{CaCO}_{3}$ "seed" features observed within some NBC pearls. However, it revealed faint growth structure within, which is rare to see in the $\mathrm{CaCO}_{3}$ seeds observed in NBC pearls. The overlapping characteristics do not correspond with the majority of structures observed in natural and NBC pearls, which could create some doubts about the identification of this pearl, leading to an inconclusive result. The circular feature in the image on the right is an artifact and should be ignored.
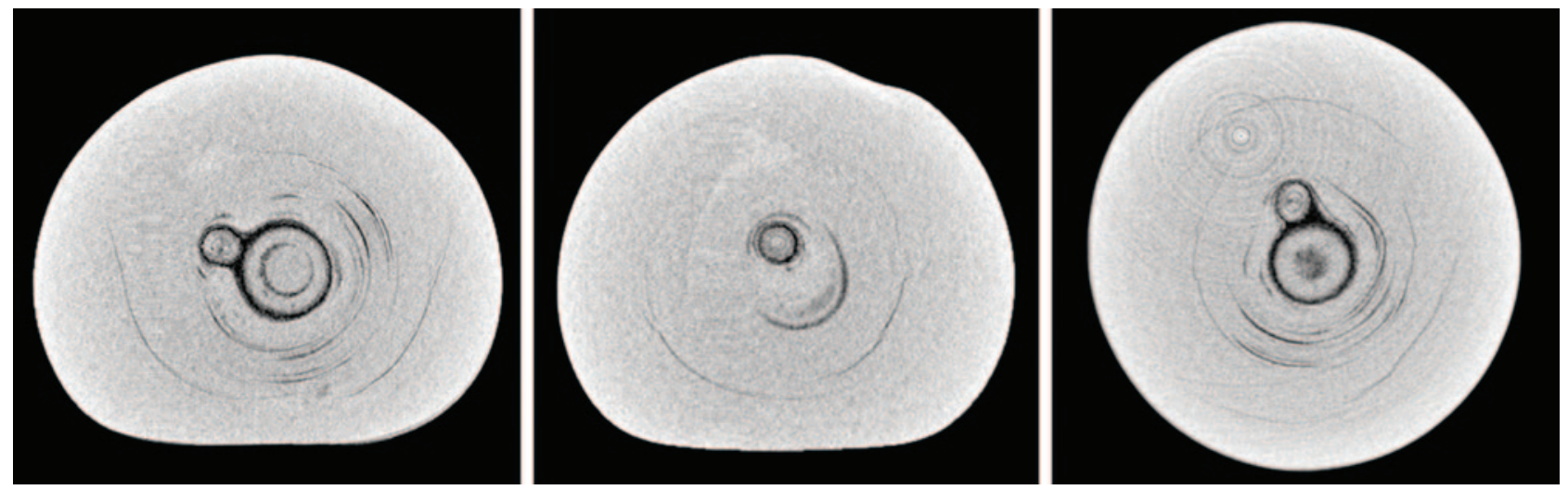


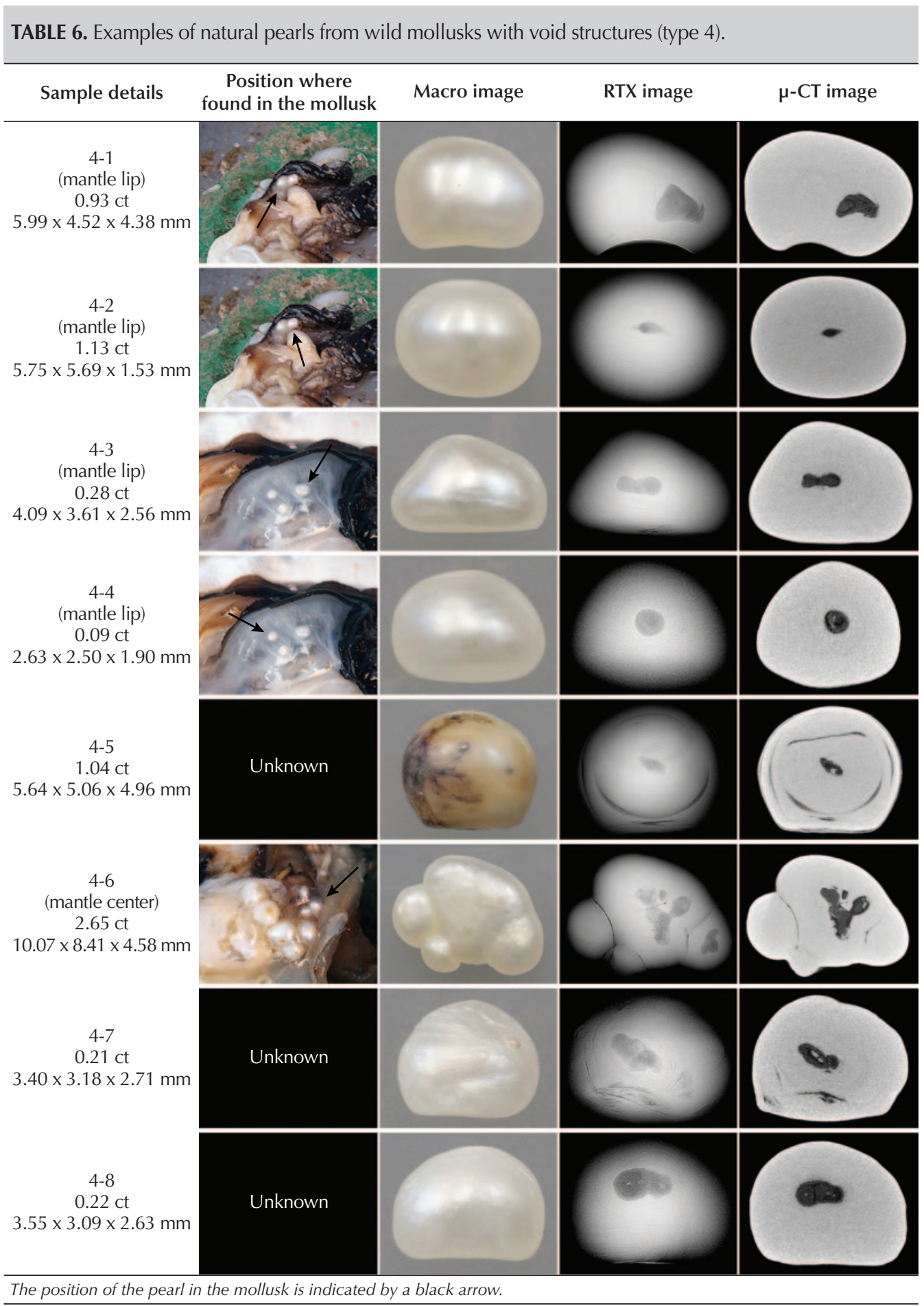

in natural and NBC pearls, an inconclusive opinion may well result.

Type 4: Void Structures. When discussing the internal characteristics of pearls, voids usually refer to radiolucent features that are less dense or more transparent to X-rays, such as cavities or areas filled with gas and/or liquid phases. Voids generally appear as various shades of dark gray, and thus they may resemble organic-rich features in low-resolution X-ray images. Voids are commonly observed in saltwater NBC pearls, especially pearls from Pinctada species 

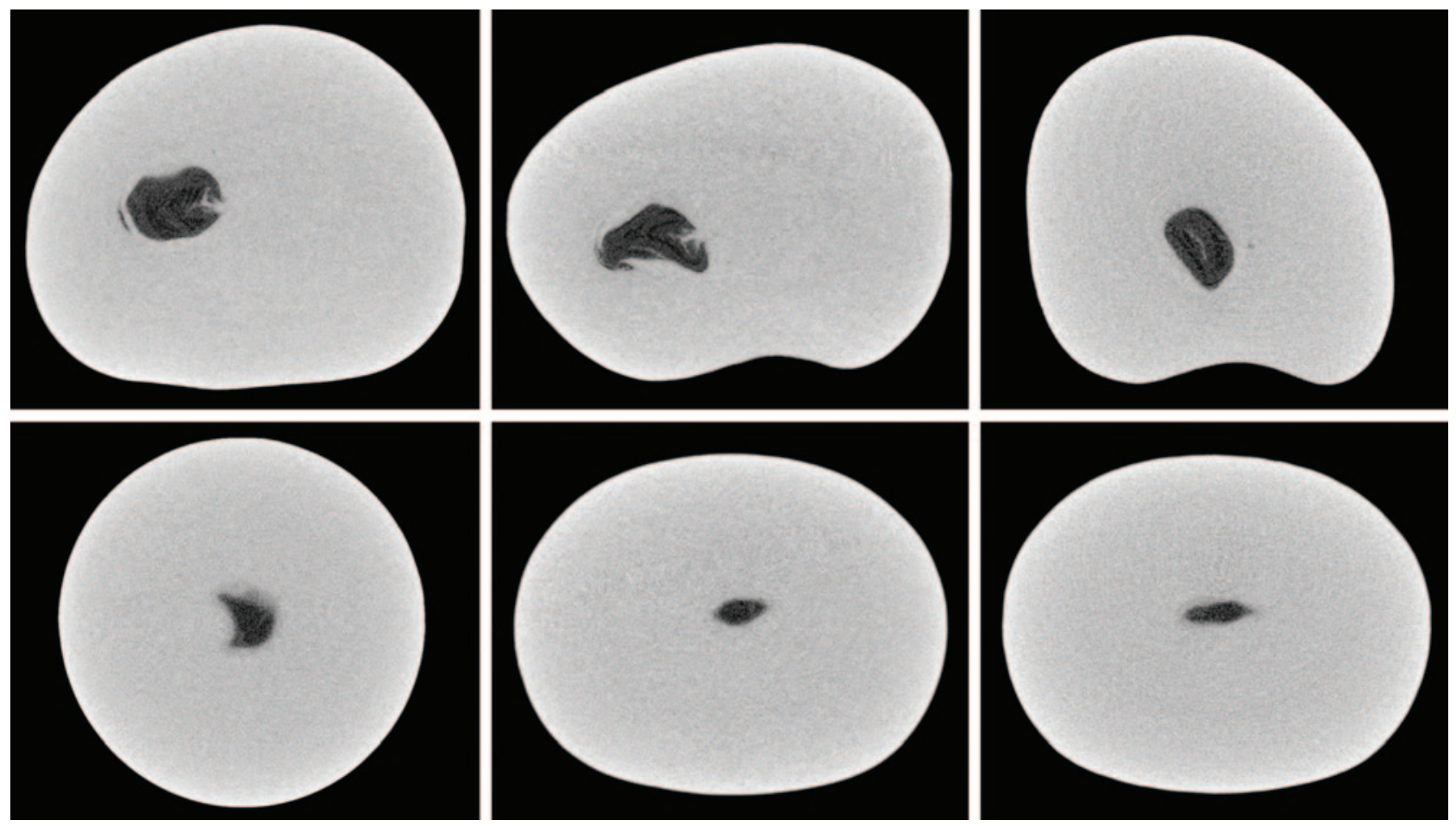

Figure 9. 1 -CT slices in three directions of samples 4-1 (top row) and 4-2 (bottom row) revealed a void feature in both. The void of sample 4-1 is filled by organic-rich features more consistent with voids found in natural pearls, whereas the void in sample 4-2 looks empty even though there are actually a few very small light gray features. The structure of 4-2 appears more NBC in nature than its twin retrieved from the pearl sac, even though it is a known natural pearl.

(Wehrmeister et al., 2008; Sturman, 2009; Krzemnicki et al., 2010; Otter et al., 2014; Sturman et al., 2016; Nilpetploy et al., 2018a; Manustrong, 2018; AlAlawi et al., 2020). In many cases, voids are a key identification feature by which to differentiate NBC from natural pearls. Only $\sim 5 \%$ of the group showed void-related characteristics, and most of these exhibited centrally positioned irregular void-like forms after RTX analysis (table 6). However, $\mathrm{\mu}-\mathrm{CT}$ analysis revealed that many of these voids were filled with fine organic-rich growth features (samples 4-1 and 43 to $4-6$ ), and some showed small light gray features in the center of organic-rich structures (samples 4-7 and 4-8) rather than the apparently empty spaces usually observed in NBC pearls. The voids are also small relative to the size of the pearl, while those found in saltwater NBC pearls tend to be larger and more elongated, extended lengthwise, usually taking up more than half of the pearl's length.

While natural voids do show some differences from those encountered in NBC pearls, identification challenges could cause some pearls to be misidentified. A couple of samples in this study showed voids similar to those characteristically found in NBC pearls, and they would almost certainly be classified as NBC if tested under blind conditions. It is interesting to note that samples 4-1 and 4-2 were retrieved from the same pearl sac and both possessed void features. However, the void in sample 4-2 does not appear to be filled with organic-rich growth structure and contains fewer light gray linear features, a common observation in NBC pearls (magnified in figure 9).

Type 5: Linear Structures. Most linear structures are thin voids, with or without organic-rich material partially filling them. Owing to the different appearances of both types of formation, they are separated into different groups in this article. Linear structures have been regarded as characteristic of NBC pearls from both saltwater and freshwater environments (Scarratt et al., 2000; Sturman, 2009; Krzemnicki et al., 2010; Sturman et al., 2016; Nilpetploy et al., 2018a; Manustrong, 2018; Al-Alawi et al., 2020).

Interestingly, 5 of the 774 natural pearl samples also displayed linear structures (table 7). Sample 5-1 
TABLE 7. Examples of natural pearls from wild mollusks with linear structures (type 5).

\begin{tabular}{|c|c|c|c|c|}
\hline Sample details & $\begin{array}{l}\text { Position where } \\
\text { found in the mollusk }\end{array}$ & Macro image & RTX image & $\mu$-CT image \\
\hline $\begin{array}{c}5-1 \\
\text { (mantle lip) } \\
1.14 \mathrm{ct} \\
6.75 \times 5.37 \times 4.51 \mathrm{~mm}\end{array}$ & & & & \\
\hline $\begin{array}{c}5-2 \\
1.61 \mathrm{ct} \\
9.50 \times 5.42 \times 4.58 \mathrm{~mm}\end{array}$ & Unknown & & & \\
\hline $\begin{array}{c}5-3 \\
\text { (mantle lip) } \\
2.03 \mathrm{ct} \\
7.38 \times 6.85 \times 5.73 \mathrm{~mm}\end{array}$ & & & & \\
\hline $\begin{array}{c}5-4 \\
\text { (mantle lip) } \\
0.26 \mathrm{ct} \\
4.91 \times 3.91 \times 2.66 \mathrm{~mm}\end{array}$ & & & & \\
\hline $\begin{array}{c}5-5 \\
0.24 \mathrm{ct} \\
3.57 \times 3.00 \mathrm{~mm}\end{array}$ & Unknown & & & $i$ \\
\hline
\end{tabular}

The positions of the pearl in the mollusk is indicated by a black arrow.

showed a complex linear feature corresponding, to some degree, with the pearl's baroque outline. In the authors' experience, such linear structures may be characteristic of NBC pearls, but this example demonstrates that is not always the case. Sample 52 consisted of three portions, two of them having a

Figure 10. $\mu$-CT slices in three directions of sample 5-2 revealed a long linear structure in the center of both parts of the pearl. These linear features could lead to it being misidentified as a NBC pearl, despite the associated growth patterns also present. The circular feature in the image on the right is an artifact and should be ignored.
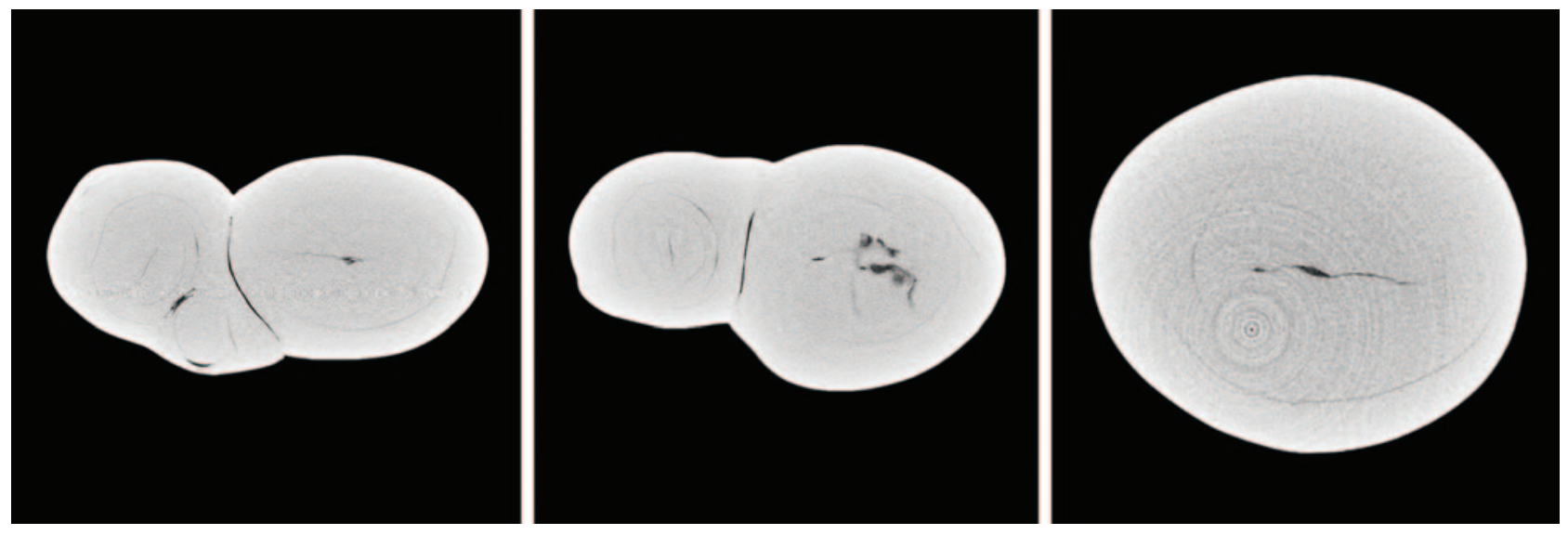
TABLE 8. Examples of natural pearls from wild mollusks with miscellaneous structures (type 6).

\begin{tabular}{|c|c|c|c|c|}
\hline Sample details & $\begin{array}{l}\text { Position where } \\
\text { found in the mollusk }\end{array}$ & Macro image & RTX image & $\mu$-CT image \\
\hline \multicolumn{5}{|c|}{ Marine organisms } \\
\hline $\begin{array}{c}6-1 \\
1.22 \mathrm{ct} \\
6.02 \times 5.73 \times 5.43 \mathrm{~mm}\end{array}$ & Unknown & & & \\
\hline $\begin{array}{c}6-2 \\
0.26 \mathrm{ct} \\
3.70 \times 3.02 \times 2.84 \mathrm{~mm}\end{array}$ & Unknown & & & \\
\hline $\begin{array}{c}6-3 \\
0.22 \mathrm{ct} \\
3.56 \times 3.07 \times 2.63 \mathrm{~mm}\end{array}$ & Unknown & & & \\
\hline $\begin{array}{c}6-4 \\
0.13 \mathrm{ct} \\
3.02 \times 2.79 \times 2.26 \mathrm{~mm}\end{array}$ & Unknown & & & \\
\hline \multicolumn{5}{|c|}{ Internal fractures } \\
\hline $\begin{array}{c}6-5 \\
\text { (attached to shell) } \\
0.54 \mathrm{ct} \\
4.66 \times 4.41 \times 3.71 \mathrm{~mm}\end{array}$ & & & & \\
\hline $\begin{array}{c}6-6 \\
0.57 \mathrm{ct} \\
5.56 \times 4.24 \times 3.48 \mathrm{~mm}\end{array}$ & Unknown & & & \\
\hline
\end{tabular}

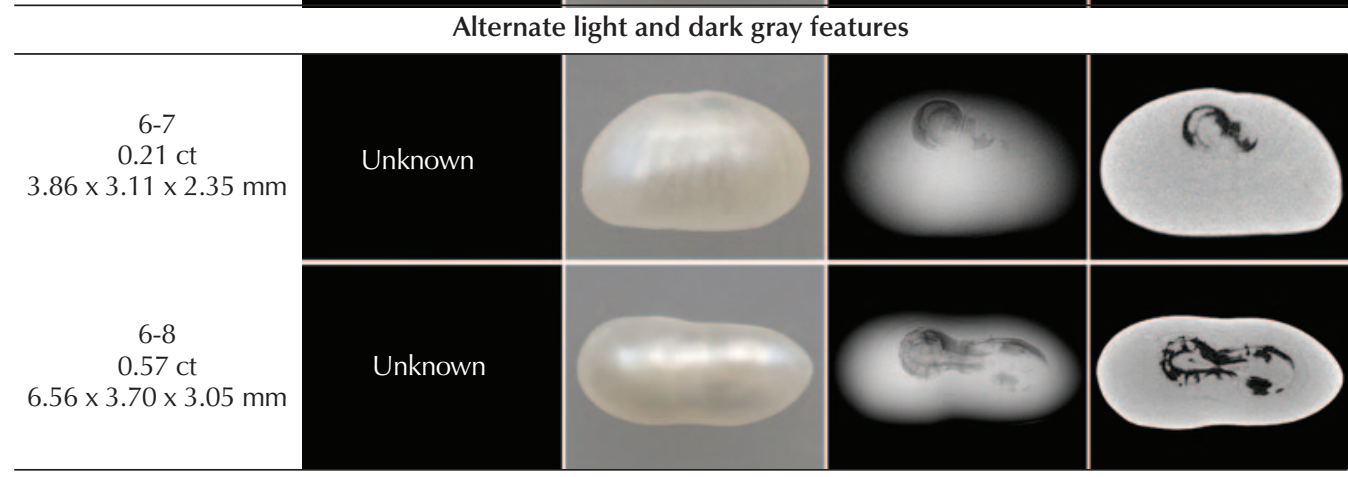

The position of the pearl in the mollusk is indicated by a black arrow.

long linear feature at the center (magnified in figure 10). Although the other portion only displayed a few growth patterns, the pearl's overall structure looked questionable and it could easily be misidentified as an NBC pearl. The linear structures revealed in samples 5-3 to 5-5 are quite distinct and correspond with the length of the pearl, a characteristic shown by many NBC pearls. 

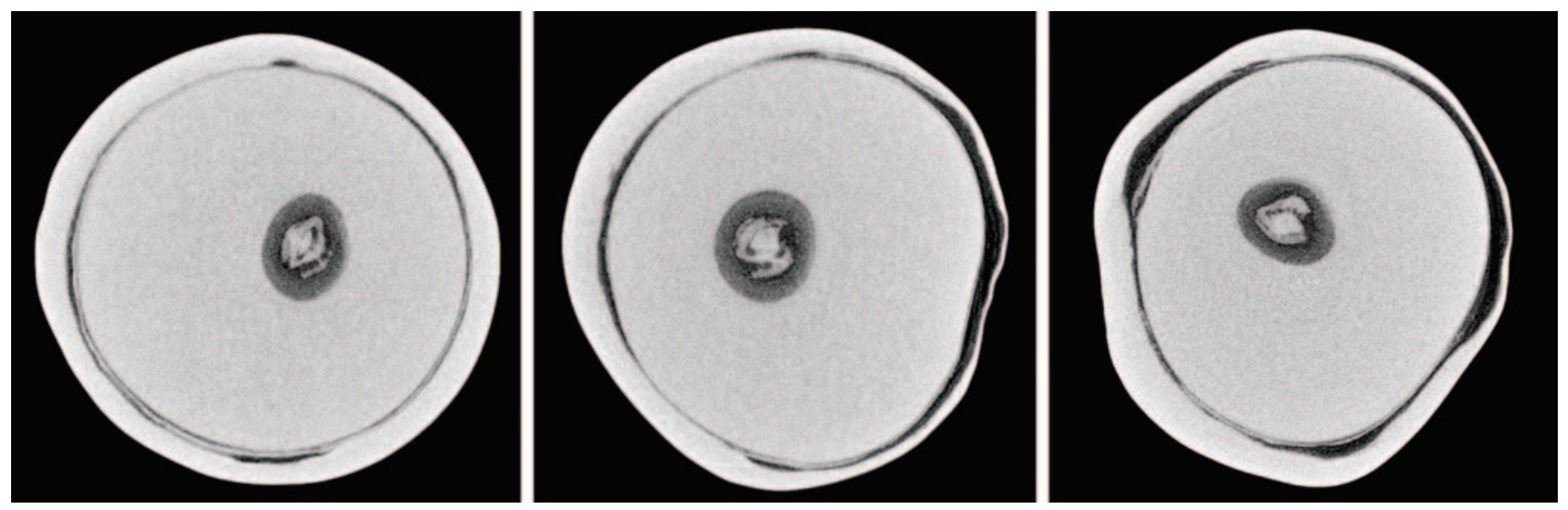

Figure 11. $\mu$-CT slices in three directions of sample 6-1 revealed a shell-like formation at its core, probably enclosed by organic-rich material. A prominent outer ring is visible in all directions, which makes the pearl look questionable. As a result, it could be misidentified as an atypical bead cultured pearl (aBCP).

Type 6: Miscellaneous Structures. The final group of natural pearls were classified as those with "miscellaneous structures." This group includes samples possibly containing marine organisms entombed by nacre deposition, examples containing obvious internal fractures, and pearls exhibiting a mixture of structures that do not readily fit into any of the former five structure types listed (table 8).

Pearls with internal features that appear to be related to marine organisms are very rare, and only a few have been encountered in the GIA laboratory from the thousands of natural pearls submitted for identification and research. Some examples have been documented in the existing literature (Scarratt et al., 2012; Nilpetploy [nee Somsa-ard], 2015). Even so, the authors were surprised to find four samples in this study group with what are most likely marine organism features. Samples 6-1 to 6-3 revealed shell-like features at their center that likely initiated the formation of the pearls, together with displaced epithelial cells. The features measured $0.78 \times 0.70 \mathrm{~mm}, 1.46$ $\times 1.34 \mathrm{~mm}$, and $0.72 \times 0.50 \mathrm{~mm}$ in diameter, respectively. The resulting pearls are similarly small. The exact identity of the marine organisms is unknown; based on the morphology observed by $\mu-\mathrm{CT}$ analysis, however, they could be one of the many benthic foraminifera species. Foraminifera are single-celled organisms (protists) with a test (shell) that can possess one or more chambers (Borrelli et al., 2018). They may be composed of organic compounds, sand grains, or other particles cemented together, or crystalline $\mathrm{CaCO}_{3}$, and are usually less than $1 \mathrm{~mm}$ in size (Steele et al., 2001). One of the existing references (Nilpetploy [nee Somsa-ard], 2015) described what was thought to be an intricate foraminifera sphere observed in a $0.95 \mathrm{ct}$ natural pearl. The core feature was encircled by a dark organic-rich area and accompanying void similar to the natural pearls described here. Sample 6-1 (magnified in figure 11) has a distinct outer ring that looks questionable and could be considered diagnostic of an atypical bead cultured pearl $(\mathrm{aBCP})$, but it does not contain an "organic tail" typ-

Figure 12. $\mu$-CT slices in three directions of sample 6-4 revealed a porous-looking structure in the main feature, possibly resembling the structure of coral from the Melithaea genus, a fan coral distributed throughout the tropical Indo-Pacific region.
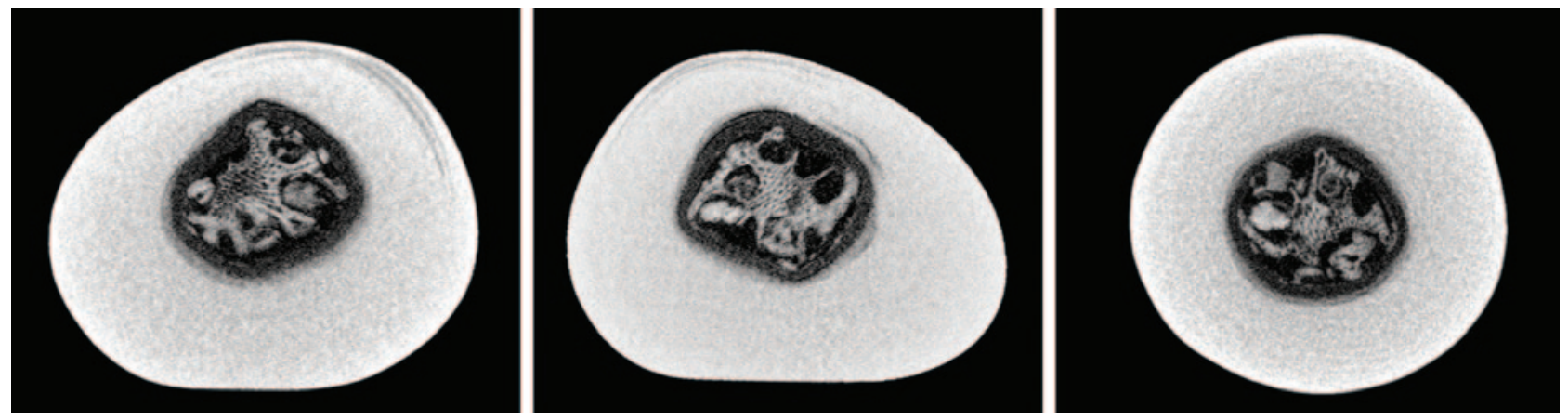

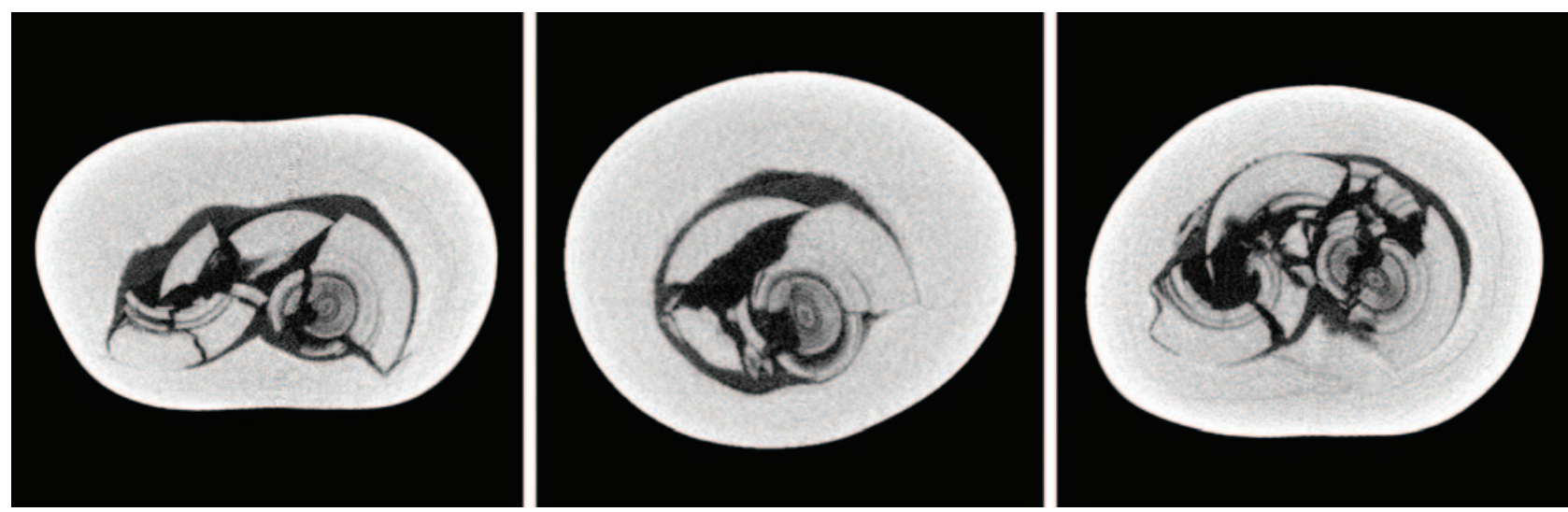

Figure 13. $\mu-C T$ slices in three directions of sample 6-6 revealed fragmented organic-rich concentric structure in the center of the pearl.

ically observed in aBCP pearls (Hänni et al., 2010; Scarratt et al., 2017; Kessrapong and Lawanwong, 2020). Therefore, it would be identified as a natural pearl, especially when its size and quality are also taken into account. Sample 6-4 displayed a large irregular radiopaque material together with some small fragments at its center. As the magnified images in figure 12 show, the material's structure differs from the three former samples, though its appearance is also likely that of a marine organism. The main feature, with its porous-looking pattern, bears some similarity to the structure of Melithaea, a genus of colonial soft coral (also known as fan coral), which is distributed throughout the tropical Indo-Pacific region (Jeong et al., 2018; Atlas of Living Australia, 2020).

Samples 6-5 and 6-6 displayed severe internal fracturing at the center of the features. X-ray computed tomography clearly revealed the intriguing structures of both pearls and indicated they were "fragmented."
It is puzzling how such broken features can exist within known natural pearls whose overlying layers of nacre appear intact and where no drilling or external treatment of any kind exist. Sample 6-6 is especially perplexing, as the naturally formed concentric organic-rich inner structure has disintegrated into many parts (magnified in figure 13) to fill the void present. This intricate structure is highly unusual, and it would be challenging to correctly identify such a pearl in laboratory testing conditions. Some of these samples could be suspected of being the result of culturing using various atypical nuclei. Yet their generally very small size would suggest otherwise, and it is known that this is definitely not the case, as they are confirmed natural pearls.

Samples 6-7 and 6-8 revealed a mixture of structures alternating between more radiopaque (light gray) and more radiolucent (dark gray) features. The structure exhibited in sample 6-7 (magnified in figure 14) appears to take the form of two initiation features

Figure 14. $\mu$-CT slices in three directions of sample 6-7 revealed two interconnected rounded initiation features in the center. The central areas in both features consist of material with the same radiopacity as the pearl's body. No characteristic NBC cultured pearl features, such as a void or linear structure, were noted. Therefore, the pearl would be classified as natural.
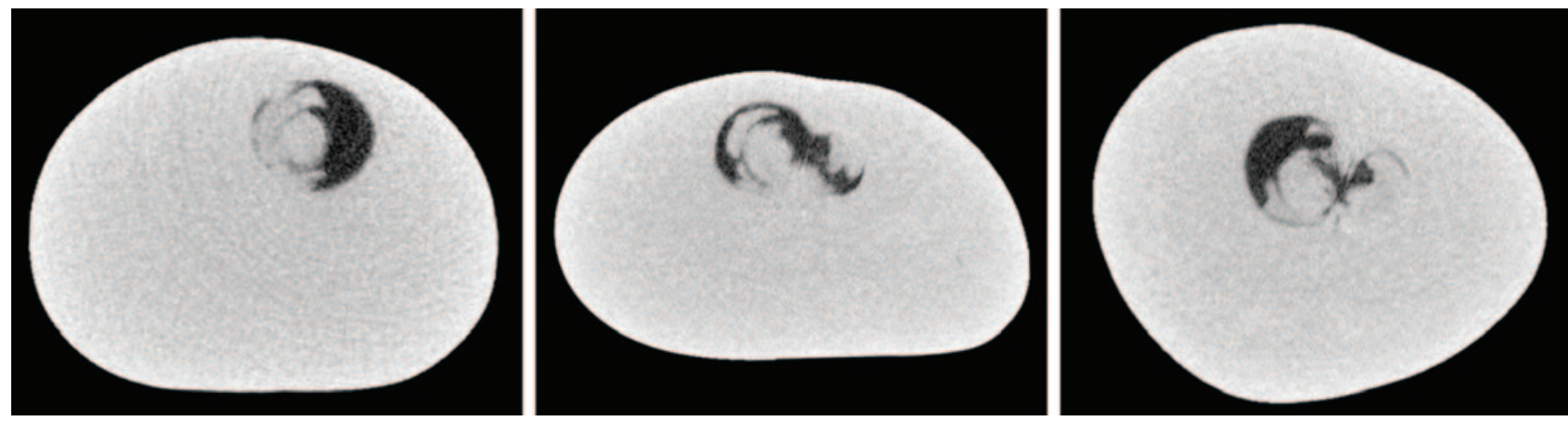

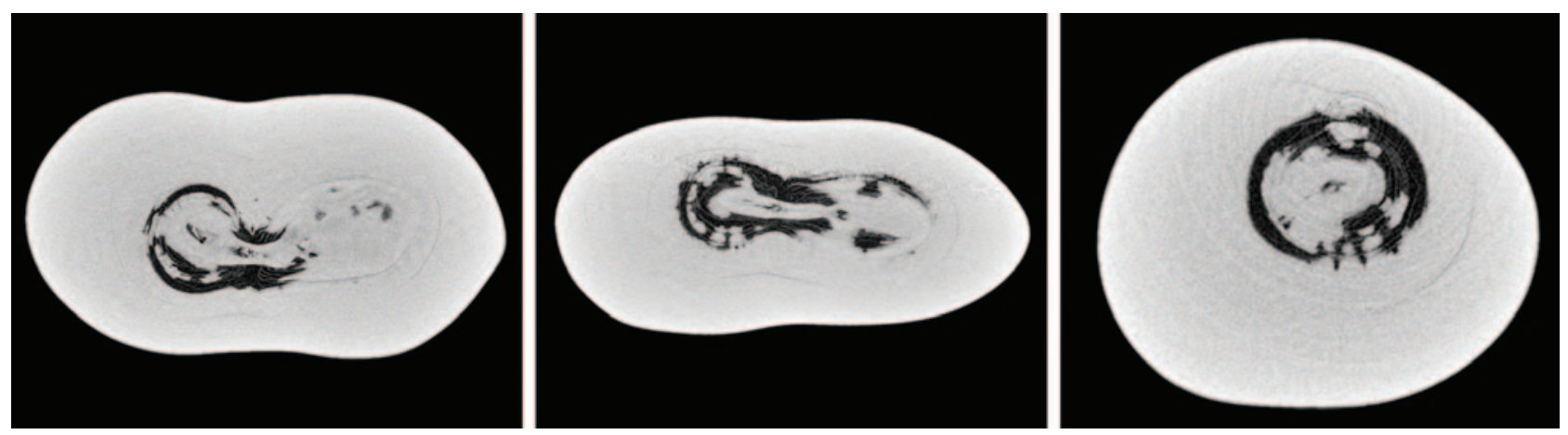

Figure 15. $\mu$-CT slices in three directions of sample 6-8 revealed a complex elongated structure consisting of a linear-like feature at its center combined with dark gray areas of voids and organic matter, and other solid light gray areas. A similar structure has been observed in some known NBC pearl samples; therefore, the identification of this pearl is challenging, and it is highly possible it would be misidentified as NBC.

merging together. Although the structure is unusual, this sample would almost certainly be identified as a natural pearl since there are no characteristic cultured pearl features such as a void or a linear structure in the center. On the other hand, sample 6-8 (magnified in figure 15) displayed a complex elongated structure consisting of a linear-like feature at its center combined with dark gray areas of voids and organic matter, as well as other solid light gray areas. Such a structure looks suspicious, and in laboratory conditions the pearl could be misidentified as NBC.

\section{DISCUSSION}

Pearl identification mainly involves separating pearls that formed naturally (figure 16) from those that resulted from a culturing process. RTX is the primary technique used in gemological laboratories to examine a pearl's internal structure, while $\mu-C T$ is a high-resolution 3D imaging technique that is sometimes used to visualize internal structures in greater detail. Interpreting the structural results obtained depends on the research and data collection of known reference samples by well-trained, experienced gemologists. Studying this large group of natural pearls provided a greater understanding about the range of microradiographic structures encountered in natural pearls produced by wild $P$. maxima mollusks. The results showed that most of the natural pearl samples $(\sim 80 \%)$ exhibited tight or minimal growth structures (type 1). These pearls are straightforward to identify as natural. This observation is also consistent with the majority of natural pearls tested in all GIA's pearl testing locations. Tight or minimal growth structure is commonly observed in natural pearls produced by many mollusk species of both nacreous and non-nacreous pearls (Krzemnicki et al., 2010; Scarratt et al., 2012; Karampelas, 2017; Nilpetploy et al., 2018b; Scarratt and Hänni, 2004; Wing Yan Ho and Zhou, 2014; Wing Yan Ho, 2015; Wing Yan Ho and Yazawa, 2017).

Organic-rich concentric structures (type 2) are also known to be typical of natural pearls produced by various mollusk species (Krzemnicki et al., 2010, Scarratt et al., 2012; Sturman et al., 2014; Karampelas et al., 2017; Nilpetploy et al., 2018b), yet they were found in only about $\sim 9 \%$ of the samples. This includes organic-rich concentric and dark gray (radiolucent) cores that are filled with organic-rich features $(\sim 4 \%)$, organic-rich concentric and light gray (more radiopaque) cores in which the majority of the cores are small and rounded $(\sim 4 \%)$, and organic-rich concentric and patchy light and dark gray structures lacking dark and light gray cores ( 1\%) (see figure 6). Most of the organic-rich concentric areas observed in natural pearls cover a relatively small portion of the pearl's interior. It is important to note that none of the pearls in this study showed any of the light gray $\mathrm{CaCO}_{3}$ "seed" features reported by Manustrong et al. (2019; see tables 4 and 5) and previously reported by other authors (Krzemnicki et al., 2010, 2011; Nilpetploy et al., 2018a) as being associated with organic-rich concentric structures in some cultured pearls. At the time of this report, the irregular dense core structures (type 3) free of any clear organic-rich concentric features are only found in natural pearls and have not been reported in NBC pearls in the literature.

Voids (type 4) and linear structures (type 5) have been reported as characteristic features in P. maxima NBC pearls (Sturman et al., 2016), but they were found in only $\sim 5 \%$ and $\sim 1 \%$, respectively, of the natural pearl 


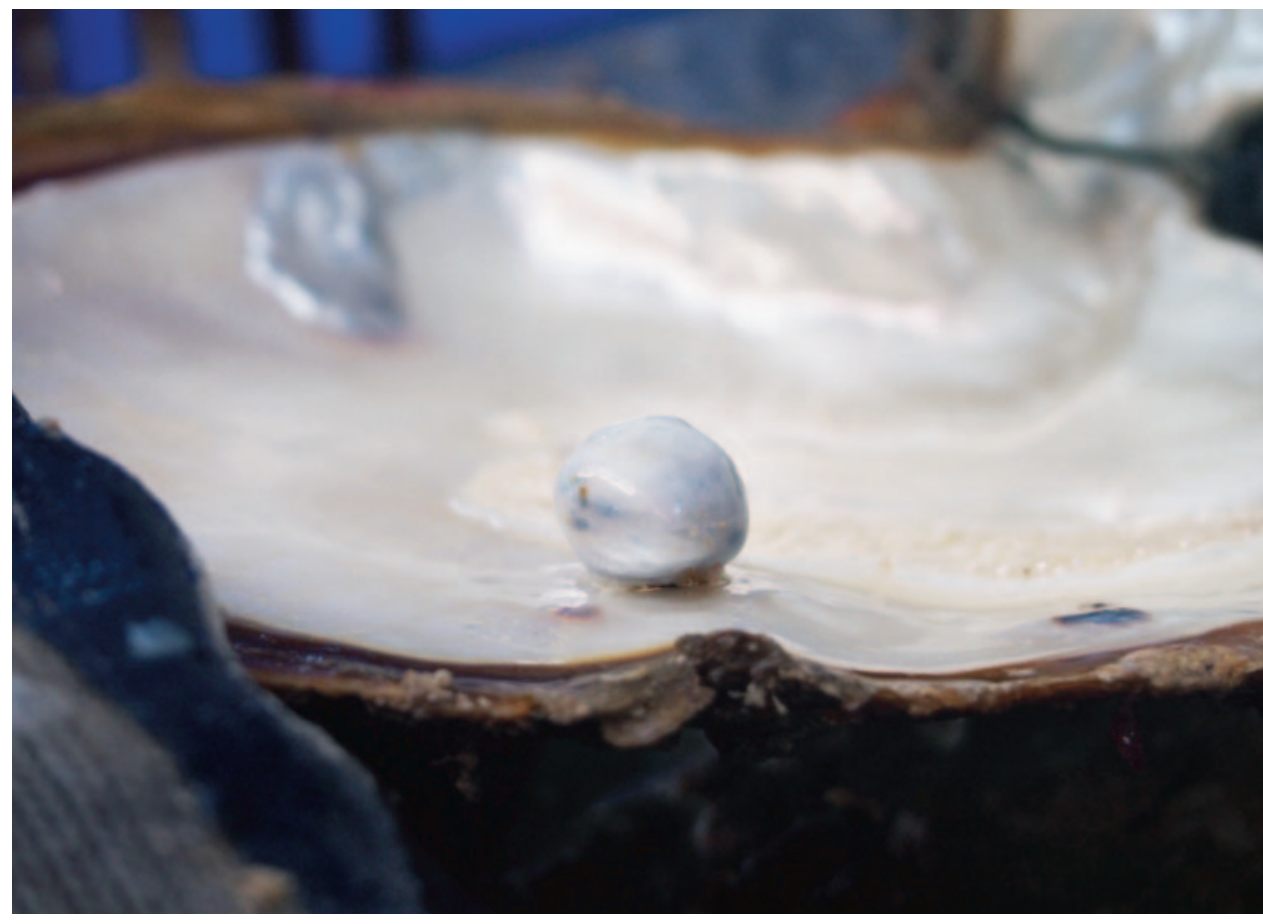

Figure 16. This $19.94 \mathrm{ct}$ pearl is the largest from the collection of 774 natural pearls collected off Eighty Mile Beach in Broome, Western Australia. The pearl was loosely attached to the shell and removed by gentle finger pressure. Photo by Areeya Manustrong.

samples in this study. Considering that the internal structural features of natural and NBC pearls may overlap, the separation between the two can be challenging and their interpretation requires extra care. While the pearls' external appearance may also assist in their identification, it is a subjective element and can vary greatly depending on the gemologist's experience. Therefore, the internal structures of pearls provide the most important evidence and consequently are the primary means of identification. In general, the void structures observed in the natural pearl samples studied occupy a relatively small volume of the pearl, and are often filled with organic-rich growth structures. The linear features are perhaps the most questionable structures found in natural pearls since the structure is widely accepted as being an identifying feature of NBC pearls produced by various mollusks. Therefore, it is possible that some or all of the five natural pearls that revealed linear structures would be identified as NBC if submitted on a "blind" basis.

In the miscellaneous structures (type 6), the presence of a marine organism-like feature as a nucleus in four samples emphasized a frequently applied hypothesis that a natural pearl forms when an external foreign object reaches the mollusk's mantle (epithelium layer), and causes the epithelial cells to encroach into the connective tissue and enclose the object to create a pearl sac, which secretes the necessary components (Kunz and Stevenson, 1908; Landman et al., 2001; Strack, 2006; Southgate and
Lucas, 2008). However, this is a rare occurrence, as only a very small number of pearls have reportedly shown this type of structure, and there are several theories about how natural pearls may form. These include: forming as a result of injury to, or abnormal growth of the epithelium cells; epithelium cells separating to form pearl sacs of their own accord; and health-related instigation. A concept mentioned in Strack (2006) may help to explain the severe internal fracturing of the features within the centers of samples 6-5 and 6-6:

If the worm larvae survive within the pearl sac or even within the growing pearl, they will usually attack or soften the surrounding pearl cover after a period of hibernation. This means that they can cause the growing pearl to break into tiny pieces, which may themselves become the reason for the formation of a new pearl sac, or will become the nucleus of a new pearl.

Lastly, the relationship between the internal structure and the position in which a pearl forms inside the $P$. maxima mollusk species is not entirely clear at this time. Since it was not possible to record the position in which over $50 \%$ of the samples were found in the mollusk's body, this question could not be addressed. Such a study would require a greater sample set of pearls with suitably accurate records. However, it was noted that most of the pearls found in the adductor muscles possessed tight or minimal growth structures, while mantle pearls generally showed a variety of structure types. 


\section{CONCLUSIONS}

The results of this study show that various forms of internal structures are observed in natural pearls. The majority of samples revealed limited growth features (minor growth patterns) or no clear structure at all (tight structure), confirming their natural identity. The relatively few samples that exhibited varying degrees of structural overlap, internal characteristics possibly observed in NBC pearls or natural pearls (i.e., off-round light gray cores in concentric organicrich structure, voids, and linear features), raised concerns about the identification of such pearls when tested without any supporting provenance information. They demonstrated the complexities often faced with pearl identification. It is not unheard of for the same pearl to receive different determinations from different organizations based on the equipment and techniques used to obtain the data, the experience and specialized knowledge of gemologists interpreting the data, and the comprehensiveness of the reference sample database. Natural pearls containing either a large void relative to the pearl's size or a distinct linear feature have a greater probability of being defined as NBC. In cases where the structures are extremely complex or ambiguous, or do not conform with anything in the database, an "inconclusive" call is likely. GIA recognizes the ongoing pearl identification challenges and intends to continue studying the internal structures of known natural and cultured pearl samples from various environments and mollusks to strengthen its reference collection and database, thus ensuring GIA's gemologists have the most up-to-date information at hand before reaching any conclusions on a client's pearl submissions.

\section{ABOUT THE AUTHORS}

Ms. Homkrajae is a senior staff gemologist at GIA in Carlsbad, California. Ms. Manustrong is a staff gemologist, Ms. Nilpetploy is a senior staff gemologist, Mr. Sturman is a consultant to GIA, and Ms. Lawanwong and Mr. Kessrapong are analytics technicians, all in GIA's Bangkok laboratory.

\section{ACKNOWLEDGMENTS}

The authors would like to extend their appreciation to Paspaley Pearling Company, Australia, for loaning the samples to GIA's Bangkok laboratory for this study and permitting GIA staff to visit Australia in order to retrieve the pearls in person. They also wish to thank Tom Moses and Kenneth Scarratt for their support and for making the trips to Paspaley possible. Lastly, we thank the peer reviewers for valuable and constructive comments that improved this article.

\section{REFERENCES}

Al-Alawi A., Ali Z., Rajab Z., Albedal F., Karampelas S. (2020) Saltwater cultured pearls from Pinctada radiata in Abu Dhabi (United Arab Emirates). Journal of Gemmology, Vol. 37, No. 2, pp. 164-179.

Alexander A.E. (1941) Natural and cultured pearl differentiation. $G \uplus G$, Vol. 3, No. 12, pp. 184-188.

Atlas of Living Australia (2020) Melithaea. Milne-Edwards \& Haime, 1857, https://bie.ala.org.au/species/urn:lsid:biodiversity.org.au:afd.taxon:8f9a2eb5-de4f-4f60-98ce-476774f63b73

Benson L.B. (1951) Gem Trade Laboratory installs new pearl testing equipment. $G \uplus G$, Vol. 7, No. 4, pp. 107-112.

Bondad-Reantaso M.G., McGladdery S.E., Berthe F.C.J. (2007) Pearl oyster health management: A manual. FAO Fisheries technical paper, No. 503, Rome, Italy, 120 pp.

Borrelli C., Panieri G., Dahl T.M., Neufeld K. (2018) Novel biomineralization strategy in calcareous foraminifera. Scientific Reports, Vol. 8, No. 1, 10201.

CIBJO, the World Jewellery Confederation (2017) The Pearl Book. CIBJO Pearl Commission.

Gervis M.H., Sims N.A. (1992) The biology and culture of pearl oysters (Bivalvia: Pteriidae). ICLARM Studies and Reviews 21, Manila, Philippines, 49 pp.

Hänni H.A. (2006) A short review of the use of "keshi" as a term to describe pearls. Journal of Gemmology, Vol. 30, No. 1/2, pp. $51-58$.
Hänni H.A., Krzemnicki M.S., Cartier L.E. (2010) Appearance of new bead material in cultured pearls. Journal of Gemmology, Vol. 32, No. 1-4, pp. 31-37.

Jeong E-A., Moon J., Hiroshi K. (2018) Akoya cultured pearls with Corallium species bead nuclei. The Journal of the Gemmological Association of Hong Kong, Vol. 39, pp. 40-44.

Karampelas S. (2017) Black non-nacreous natural pearls from Pteria sp. Journal of Gemmology, Vol. 35, No. 7, pp. 590-592.

Karampelas S., Michel J., Zheng-Cui M., Schwarz J.-O., Enzmann F., Fritsch E., Leu L., Krzemnicki M.S. (2010) X-ray computed microtomography applied to pearls: Methodology, advantages, and limitations. Ge $G$, Vol. 46, No. 2, pp. 122-127, http://dx.doi.org/10.5741/GEMS.46.2.122

Karampelas S., Al-Alawi A.T., Al-Attawi A. (2017) Real-time microradiography of pearls: A comparison between detectors. $G \uplus G$, Vol. 53, No. 4, pp. 452-456, http://dx.doi.org/10.5741/GEMS.53.4.452

Kessrapong P., Lawanwong K. (2020) Atypical bead cultured Pinctada maxima pearls nucleated with freshwater non-bead cultured pearls. GIA Research News, April 6, https://www.gia.edu/gianews-research/atypical-bcp-nucleated-with-nbcp

Krzemnicki M., Friess D., Chalus P., Hänni H.A., Karampelas S. (2010) X-ray computed microtomography: Distinguishing natural pearls from beaded and non-beaded cultured pearls. $G \uplus G$, Vol. 46, No. 2, pp. 128-134, http://dx.doi.org/10.5741/GEMS.46.2.128 
Krzemnicki M.S., Müller, Hänni H.A., Gut H.-P., Düggelin M. (2011) Tokki pearls: Additional cultured pearls formed during pearl cultivation: External and internal structures. 32nd International Gemmological Conference, https://www.ssef.ch/wpcontent/uploads/2018/01/SSEF_Tokki_pearls.pdf

Kunz G.F., Stevenson C.H. (1908) The Book of the Pearl. The Century Co., New York, 548 pp.

Landman N.H., Mikkelsen P.M., Bieler R., Bronson B. (2001) Pearls: A Natural History. Harry N. Abrams, Inc., New York, $232 \mathrm{pp}$.

Lawanwong K., Nilpetploy N., Manustrong A., Homkrajae A. (2019) Natural shell blisters and blister pearls: What's the difference? GIA Research News, August 26, https://www.gia.edu/gia-news-research/natural-shell-blistersand-blister-pearls

Manustrong A. (2018) Gems News International: Very small akoya cultured pearls. Ge G, Vol. 54, No. 1, pp. 103-105, https://www.gia.edu/gems-gemology/spring-2018-gemnewsvery-small-akoya-cultured-pearls

Manustrong A., Kessrapong P., Lawanwong K., Nilpetploy N., Homkrajae A. (2019) Known non-nacreous non-bead cultured pearls and similar unknown pearls of likely cultured origin from Pinctada maxima. GIA Research News, September 4, https://www.gia.edu/gia-news-research/known-non-nacreousnon-bead-cultured-pearls

Nilpetploy N., Lawanwong K., Kessrapong P. (2018a) Non-bead cultured pearls from Pinctada margaritifera. GIA Research News, April 27, https://www.gia.edu/ongoing-research/nonbead-cultured-pearls-from-pinctada-margaritifera

- (2018b) The gemological characteristics of Pipi pearls reportedly from Pinctada maculata. Ge G, Vol. 54, No. 4, pp. 418-427, http://dx.doi.org/10.5741/GEMS.54.4.418

Otter L.M., Wehrmeister U., Enzmann F., Wolf M., Jacob D.E. (2014) A look inside a remarkably large beaded South Sea cultured pearl. $G \uplus G$, Vol. 50, No. 1, pp. 58-62, http://dx.doi.org/10.5741/GEMS.50.1.58

Pardieu V., Rakotosaona N. (2012) Ruby and sapphire rush near Didy, Madagascar. GIA Research News, October 15, https://www.gia.edu/gia-news-research-nr101512

Scarratt K., Hänni H.A. (2004) Pearls from the lion's paw scallop. Journal of Gemmology, Vol. 29, No. 4, pp. 193-203.

Scarratt K., Karampelas S. (2020) Pearls evolution in the sector, production and technology. InColor, Spring/Summer, pp. 8286.

Scarratt K., Moses T.M., Akamatsu S. (2000) Characteristics of nuclei in Chinese freshwater cultured pearls. $G \uplus G$, Vol. 36, No. 3, pp. 98-109, http://dx.doi.org/10.5741/GEMS.36.2.98

Scarratt K., Bracher P., Bracher M., Attawi A., Safar A., Saeseaw
S., Homkrajae A., Sturman N. (2012) Natural pearls from Australian Pinctada maxima. GÆG, Vol. 48, No. 4, pp. 236-261, http://dx.doi.org/10.5741/GEMS.48.4.236

Scarratt K., Sturman N., Tawfeeq A., Bracher P., Bracher M. Homkrajae A., Manustrong A., Somsa-ard N., Zhou C. (2017) Atypical "beading" in the production of cultured pearls from Australian Pinctada maxima. GIA Research News, February 13, https://www.gia.edu/gia-news-research/atypical-beadingproduction-cultured-pearls-australian-pinctada-maxima

Somsa-ard N. (2015) Lab Notes: A natural pearl with an intriguing internal structure. $G \uplus G$, Vol. 51, No. 4, pp. 434-436.

Southgate P.C., Lucas J.S (2008) The Pearl Oyster. Elsevier, Oxford, $574 \mathrm{pp}$.

Steele J.H., Thorpe S.A., Turekian K.K. (2001) Encyclopedia of Ocean Sciences. Elsevier, Amsterdam.

Strack E. (2006) Pearls. Rühle-Diebener, Stuttgart, Germany.

Sturman N. (2009) The microradiographic structures of non-bead cultured pearls. GIA Research News, November 20, https://www.gia.edu/gia-news-research-NR112009

Sturman N., Homkrajae A., Manustrong A, Somsa-ard N. (2014) Observations on pearls reportedly from the Pinnidae family (Pen pearls). GeG, Vol. 50, No. 3, pp. 202-215, http://dx.doi.org/10.5741/GEMS.50.3.202

Sturman N., Bergman J., Poli J., Homkrajae A., Manustrong A. Somsa-ard N. (2016) Bead-cultured and non-bead-cultured pearls from Lombok, Indonesia. Ge G, Vol. 52, No. 3, pp. 288 297, http://dx.doi.org/10.5741/GEMS.52.3.288

Vertriest W., Palke A.C., Renfro N.D. (2019) Field gemology: Building a research collection and understanding the development of gem deposits. $G \uplus G$, Vol. 55, No. 4, pp. 490-511, http://dx.doi.org/10.5741/GEMS.55.4.490

WAMSC, Western Australian Marine Stewardship Council (2015) MSC offers a pearler of an opportunity for gem producers. Latest News, August 28, http://www.wamsc.com.au/news/mediaitem.phtml?MediaID $=37$

Webster R. (1950) London Laboratory's new X-ray equipment. Ge) G, Vol. 6, No. 9, pp. 279-281.

Wehrmeister U., Goetz H., Jacob D.E., Soldati A., Duschner W., Xu H., Hofmeister W. (2008) Visualization of the internal structures of cultured pearls by computerized X-ray microtomography. Journal of Gemmology, Vol. 31, No. 1/2, pp. 15-21.

Wing Yan Ho J. (2015) Lab Notes: Large natural quahog pearl. $G \uplus G$, Vol. 51, No. 1, pp. 63-64.

Wing Yan Ho J., Zhou C. (2014) Lab Notes: Natural pearls reportedly from a Spondylus species ("thorny" oyster). Ge $G$, Vol. 50, No. 3, pp. 241-242.

Wing Yan Ho J., Yazawa E. (2017) Lab Notes: Natural conch "rosebud" pearls. $G \uplus G$, Vol. 53, No. 2, pp. 230-231.

For online access to all issues of GEMS \& GEMOLOGY from 1934 to the present, visit: gia.edu/gems-gemology 